\title{
An integrated approach to study the impact of fractures distribution on the Ilam-Sarvak carbonate reservoirs: a case study from the Strait of Hormuz, the Persian Gulf
}

\author{
Ehsan Kosari ${ }^{1}$, Ali Kadkhodaie-Ilkhci*2,3 ${ }^{2,}$ Abbas Bahroudi ${ }^{4}$, Ali Chehrazi ${ }^{5}$, Morteza Talebian ${ }^{1}$ \\ ${ }^{1}$ Research Institute for Earth Sciences, Geological Survey of Iran, Tehran, Iran \\ ${ }^{2}$ Earth Science Department, Faculty of Natural Science, University of Tabriz, Tabriz, Iran \\ ${ }^{3}$ Department of Petroleum Engineering, Curtin University, Perth, Western Australia \\ ${ }^{4}$ Department of Mining and Exploration, Faculty of Engineering, University of Tehran, Tehran, Iran \\ ${ }^{5}$ Departmant of Geophysics, Iranian Offshore Oil Company, Tehran, Iran
}

\begin{abstract}
Most of the Iranian hydrocarbon reservoirs in the Persian Gulf Basin and the Zagros Fold-Thrust Belt are composed of fractured carbonate rocks. In this regard, determining the spatial distribution of fractures has been a challenging issue. In this study, an integrated approach was applied for understanding the impact of fractures spatial distribution on the Ilam-Sarvak (Cenomanian to Santonian) carbonate reservoir rocks. For this purpose, seismic interpretation techniques along with geomechanical and geostatistical modeling were employed to characterize fractures at different scales.

Initially, the relationship between fractures origin and the normal faults was investigated by conducting an in-situ stress analysis. Afterwards, the velocity deviation log (VDL) and fracture intensity log (FIL) were derived as fracture attributes from the interpretation of Formation Micro Imager (FMI) and conventional well logs. A 3D model of VDL and FIL was achieved by using a sequential Gaussian
\end{abstract}

\footnotetext{
*Corresponding author: Tel: +98912638 3051

kosari.e@alumni.ut.ac.ir (Ehsan Kosari), kadkhodaie_ali@tabrizu.ac.ir \& ali.kadkhodaie@curtin.edu.au (Ali Kadkhodaie), bahroudi@ut.ac.ir (Abbas Bahroudi), achehrazi@iooc.co.ir (Ali Chehrazi), talebian@gsi.ir (Morteza Talebian)
} 
simulation (SGS) method. In order to achieve a more realistic and accurate model of the factures distribution, variations of the shear-wave velocity and geomechanical properties (Young's modulus and Poisson's ratio) were estimated by applying the advanced seismic interpretation techniques in the normal faults domain. The results show that the intensity of fractures increases once they are introduced to the normal faults, especially in the central part of the study area around well\#2. Such a fractured zone is verified by fracture density log derived from FMI logs of the mentioned well. Obviously, there is a closeknit relationship between the fracture system and the normal faults.

Eventually, secondary porosity caused by features was determined though identification of Hydraulic Flow Units (HFUs). Based on the porosity and permeability data, seven HFUs were determined for the Ilam-Sarvak reservoirs. The very high values of Log FZI indicate the possible presence of fractures. Overall, the fractures contributed to enhance the secondary porosity of the reservoir rocks though increasing matrix permeability. To sum up, the fractures system plays a critical role in controlling reservoir properties especially in the hanging-wall of normal faults where the majority of the macro and micro fractures are distributed.

Keywords: Fractured reservoir, Reservoir modeling, Rock physics, Geomechanics, Persian Gulf, IlamSarvak

\section{Introduction}

Carbonate reservoirs contain more than 50 percent of the oil and gas reservoirs of the world (Dou et al., 2011). Most of the Iranian hydrocarbon fields in the Persian Gulf Basin and the Zagros Folded-Thrust Belt belong to this category of reservoirs, and approximately 95 percent of the oil is accumulated in the Asmari, Ilam and Sarvak limestone formations (Bordenave and Hegre, 2010). Carbonate formations comprise the principal Iranian oil reservoirs. As a result of regional tectonic activities such carbonates rocks are highly fractured the majority of oil and gas reservoirs production in Iran is attributed to fractures role. 
Structurally complex reservoirs are a set of reservoirs in which fracture and fault systems play a crucial role. By definition, fractured reservoirs are a subset of structurally complex reservoirs in which regularly spaced fractures and fault sets play a substantial role in production, trapping and fluid flow (Jolley et al., 2007).

Fluid containment and flow in fractured reservoirs occurs both within the fracture system and within the matrix and thus the characteristics of both the fractures and the matrix need to be assessed. The study of fractured reservoirs is therefore more time-consuming and more difficult compared to matrix-controlled reservoirs (Nie et al., 2013; Nelson, 2001). Each class of fault and fracture within the reservoir has its own special characteristics (geometry, aperture, spacing, distribution, connectivity, and hydraulic properties), each of which can improve or degrade the quality of the reservoir (Aydin, 2000).

The process of fractures evaluation in reservoirs initially starts with fractures identification, followed by determining the impact of those fractures upon reservoir performance. Nelson (2001) has identified four types of reservoirs based on fractures distribution. Type 1: Reservoirs in which fractures provide the essential reservoir porosity and permeability. Type 2: Reservoirs in which fractures provide the essential reservoir permeability. Type 3: Reservoirs in which fractures assist permeability in an already producible reservoir. Type 4: Reservoirs in which fractures provide no additional porosity or permeability but create significant reservoir anisotropy (barriers).

The physical characteristics of fractures are affected by their origin; the mechanical properties of the host rock and digenetic processes and these factors can increase or decrease the porosity and permeability (Nelson, 2001). Naturally fractured rocks can be divided into three main categories based on the type of their porosity (Tiab and Donaldson, 2011). a) intercrystalline-intergranular, such as the Snyder field in Texas, the Elk Basin in Wyoming, and the Umm Farud field in Libya, b) fracture-matrix, such as, the Spraberry field in Texas, the Kirkuk field in Iraq, the Dukhan field in Qatar, c) vugular-solution, such as, the Pegasus Ellenburger field and the Canyon Reef field in Texas. 
Reservoir engineers and petrophysicists have constantly been concerned with evaluating fractured reservoirs and predicting the three-dimension spatial distribution of fractures. There are a variety of techniques for fracture evaluation and its spatial distribution modeling. These include; field study, coring, well-log data, production data, mud loss, wellbore images (Tokhmechi et al., 2010, Lacombe et al., 2011; Khoshbakht et al., 2012 ), microseismicity recordings (Sausse et al., 2010; Dorbath et al., 2009), discrete fracture modeling (Dershowitz et al., 2000; Sabathier et al., 1998), amplitude variations, scattered waves, elastic waves and seismic attribute (Tsvankin et al., 2012; Karimpouli et al., 2013; Bellefleur et al., 2012; Malehmir and Bellefleur, 2009; Al-Dossary and Marfurt, 2006; Chopra and Marfurt, 2010; Chopra et al., 2011; Roberts, 2001). Applying each approach for fracture study alone increases probability of error and can result in a high level of uncertainty. Each of the mentioned methods has its own limitations; for example, the use of seismic approach requires high-quality data, any study using conventional logs has a low spatial resolution and fracture prediction with curvature does not reveal fractures status (open or filled), beside, calculation of curvature alone in order to predict fracture intensity overlooks other factors affecting development (Kosari et al., 2015; Jenkins et al., 2009). Cores provide the most direct data; however, the disadvantage of core analysis is the difficulty in assessing the representativeness of the core plugs. Moreover, the original geometry of the fractures is often lost in the process of recovery and the high cost of core analysis (Zazoun, 2013). Likewise, using well log data alone does not provide robust results in inter-well zones. It follows that no reliable results can be obtained by using a single approach. To successfully predict fracture distribution several evaluation scales should be considered ranging from centimeter to kilometer. Hence, applying well data (centimeter/millimeter scales) and seismic data (meter/kilometer scale) seems indispensable.

The current study presents an integrated approach which considers multiple investigation scales ranging from millimeter to kilometer scales for fractures study and their impact on reservoir quality. The integrated approach enables us to provide a more realistic model of fractures spatial distribution in the Ilam-Sarvak carbonate reservoirs. 


\section{Geological Background}

According to Berberian (1995) and Falcon (1974), the Zagros basin contains five subdivisions; the Zagros Imbricate Zone, the Zagros Simply Folded Belt, the Zagros foredeep, the Mesopotamian and the Persian Gulf foreland basins and Arabian platform. The Zagros fold-thrust belt is deforming as a result of the convergence of the Arabian and Eurasian Plate (Fig. 1a), which is the most prevalent shortening occurring in the Persian Gulf (about 20mm/yr) (McQuarrie et al., 2003; Vernant et al., 2004; Allen et al., 2004; Regard et al., 2004; Vernant et al., 2004). The Persian Gulf basin is approximately $2600 \mathrm{~km}$ long and 900 to $1900 \mathrm{~km}$ wide (Edgell, 1996), and is surrounded by Arabian Shield in the west, Taurus Mountains in the north and Zagros Mountain in the East and northeast (Konyuhov and Maleki., 2005). The Petroleum systems in the Persian Gulf with the northwest-southeast trend have diverse properties and show variations in reservoir zones, cap rocks, source rocks, participation or non-participation of Hormuz salt diapir in the reservoir's structure and the effect of different orogenies (Zagros and Oman orogeny).

The studied reservoir is located close to the Strait of Hormuz in the eastern Persian Gulf basin (Fig.1a, b). Tectonically, the hydrocarbon field is situated on the Arabian Plate where a large proportion of the Middle East hydrocarbon reserves occur (Fig. 1a). The area has been affected by two tectonic systems, the Zagros and Oman orogenies each of which has imposed individual structural trends; NW-SE and N-S, respectively. The structural trend is approximately North-South and parallel to the Oman mountains. Two major sets of faults affected and formed the final field geometry. The dominant set trends N-S and two faults of this set bound the field. They include the main eastern fault which dips steeply to the east and shows dip-slip reverse movement and the main western fault which also dips steeply to the east but shows inverted sense of movement (normal to reverse). Another set of normal faults show northwest-southeast trends.

Stratigraphically, the Sarvak and Ilam formations which were deposited on a carbonate platform and are Middle to Upper Cretaceous in age (Cenomanian to Santonian, Fig. 2), constitute the productive field zones in the eastern Persian Gulf. In the Iranian reservoirs, after the Asmari Formation, the Sarvak carbonate reservoir contains the most hydrocarbon accumulations. The emergence of the Sarvak 
carbonates was caused by three factors: (1) a fall in sea level, (2) salt tectonics and (3) uplift. Uplift and erosion resulted in the development of a vuggy and cavernous porosity and karst formation (Hajikazemi et al., 2010). In the type section (Bangestan Mountain) the Sarvak Formation (Cenomanian-Turonian) has a thickness of about $800 \mathrm{~m}$ (Motiei, 1993). The lower part of the Formation (about $255 \mathrm{~m}$ ) consists of argillaceous limestones with lenticular bedding and thin marl inter-beds. The middle part with about 525 m thickness consists of massive chalky limestones with iron-rich siliceous nodules and rudist fragments. The top $42 \mathrm{~m}$ of the Formation consists of massive limestones and the topmost strata comprise a weathered, brecciated ferruginous limestone. In some areas of southern Iran and the Persian Gulf (as well as SE Iraq, Kuwait and other areas), the Ahmadi Member (mid-Cenomanian) is present and is composed of shale and marl (e.g. Sharp et al., 2010; van Buchem et al., 2010). The type section of the Ilam carbonate Formation is located in the Lurestan Province and it is underlain by the Surgah Formation and overlain by the Gurpi Formation.

The Sarvak Formation in the hydrocarbon field of the study area is subdivided into three members (Fig. 2); the Mishrif member with white to brown limestone; the Khatiyah member with gray limestone and finally the Mauddud member consisting of brown to gray limestones. The Ilam Formation is also comprised of limestone lithology (Fig.2).

\section{Methods and materials}

Initially, the position of the main faults in the field was determined by using the $2 \mathrm{D}$ seismic profiles and Underground Contour (UGC) maps. An attempt was then made to establish a genetic link between the fractures and main faults. The surveying of the fractures achieved using a Formation Micro Imager (FMI) (water based drilling fluid) in three wells. The resulting Image logs are advanced, modern logs and provide high-resolution oriented images (Serra, 1989). In addition, the orientation of the horizontal principal stresses were determined by separating the types of failure (see Barton and Zoback, 2002; Tingay et al., 2005; Tingay et al., 2006; Rajabi et al., 2010; Nie, 2013) and examining the genetic and geometric relationships between the fractures and major faults. 
In this study, direct and indirect fracture indicators including fracture intensity log (FIL) and Velocity Deviation logs (VDL) were computed and modeled. The velocity-deviation logs, which are calculated by combining sonic logs with the neutron-porosity or density logs, provide a tool that can be used to obtain downhole information on the predominant pore type in carbonates (Anselmetti and Eberli, 1999). The FILs are derived from the processing of wellbore images.

Afterwards, fractures were characterized in inter-well spaces by using seismic interpretation and attributes technology. A seismic attribute is defined as a quantitative measure of a seismic characteristic of interest (Chopra and Marfurt, 2005). They are specific quantities of geometric, kinematic, dynamic or statistical features derived from seismic data. Analysis of seismic attributes could improve interpretation of geological features. For creating the shear-wave velocity and geomechanical properties from seismically derived attributes a model-based algorithm was employed.

An important step is establishing the possible links between fractures and the major geological structures (faults in this case). According to Harris et al., (1960), if fractures are associated with major structures, they will be mainly situated along the regional tectonic features. In addition to studying the connection between the faults and fractures, it is then necessary to investigate the impact of fractures on the reservoirs properties. The relationship between fracture intensity, reservoir permeability and porosity can be determined through interpretation of FMI logs (Full-bore Formation Micro-imager) and Routine Core Analysis (RCAL) data. Well\#1 from the study area contains both of the dataset.

Finally, an attempt has been made to categorize fracture based on different indexes. In the simplest method, porosity and permeability values of fractures are sorted on the basis of type of fracture (horizontal, open and micro). The alternative technique is clustering fracture parameters by using KMeans method (Hartigan and Wong, 1979). Through K-means method data can be divided into several clusters, the members of each cluster are homogeneous internally and heterogeneous, externally from other clusters. The other technique is defining Hydraulic Flow Unit for fractures characterization. Unlike the previous studies, this technique is only used for the recognition of fractures based on permeability to porosity ratio which will be discussed later. 


\section{Data Analysis and Discussion}

\subsection{Relationship between faults and fractures system by using in-situ stress analysis}

As a matter of fact, investigation and identification of fractures set within a reservoir is of prime importance. The present-day horizontal stress orientations were determined from borehole breakouts and drilling induced fractures interpreted from FMI log data. It is assumed that natural fracture patterns depict the local state of stress at the time of fracturing and that subsurface rocks are fractured in a manner qualitatively similar to equivalent rocks in laboratory tests performed at analogous environmental conditions (Nelson, 2001). Drilling-induced fractures are created where the wellbore stress concentration is less than the tensile strength of the rock and they are oriented in the $S_{\mathrm{Hmax}}$ direction. Breakouts occurred where stresses concentrated at the wellbore wall exceed the compressive strength of the rock causing failure of intact rock and they are elongated perpendicular to $S_{\mathrm{Hmax}}$ direction (Zoback, 2007; Tingay, 2005; Aadnoy, 1990; Bell and Gough, 1979).

A study of seismic profiles and UGC maps (Fig. 3) reveals the presence of two faults sets, one with NS strike (eastern reverse fault and western inverted reverse fault) and the other with NW-SE strike (internal normal faults). In order to determine the horizontal stresses surveys were conducted on FMI logs to identify the different types of fractures. Open fractures, drilling-induced fractures and breakouts were recognized (Fig. 4). It is found that the general trend of the natural fractures is approximately similar to the drilling induced fractures (DIFs) and the maximum horizontal stress $\left(\mathrm{S}_{\mathrm{Hmax}}\right)($ Fig. 5). The trend of the observed internal normal faults in the hydrocarbon field (Figs. 1c \& 3) follow the same trend and it is therefore possible that the fractures are associated with available faults. The FMI logs of three wells were used to validate such an observation. It was observed that the density and distribution of fractures in well $\# 1$ and \#2, which are closer to the faults, are much more than well \#3 which has been drilled outside of the faults domain.

\subsection{Geostatistical Modeling of fractures}

Several algorithms have been devised to create stochastic simulations. One of the most widely used is the Sequential Gaussian Simulation (SGS), however, it is impractical when considering multi-scale data, 
particularly when the data do not average linearly (Manchuk et al., 2005). This method is simple, flexible, and reasonably efficient (Pyrcz and Deutsch, 2014; Hu and Ravalec-Dupin, 2005) and is currently the prevalent static simulation algorithm used in reservoir modeling. In a typical SGS study, the procedure is applied to volume-averaged rock properties and is performed at the nodes of a regular grid (Srivastava et $a l ., 2005)$. In this study, geostatistical simulation was used to create a 3D spatial model of the velocity deviation $\log (\mathrm{VDL})$ and fracture intensity $\log (\mathrm{FLI})$.

\subsubsection{The Velocity Deviation Log Model}

The VDL is calculated by converting porosity-log data to a synthetic velocity log by using a timeaverage equation (Wyllie and Gardner., 1956) (Eq. 1):

$$
\text { Eq. 1. } \frac{1}{\text { Vrock }}=\frac{1-\emptyset}{\text { Vmatrix }}+\frac{\emptyset}{\text { Vfluid }}
$$

where $\mathrm{V}$ and $\varphi$ are velocity and porosity, respectively. The difference between the real sonic log and the synthetic sonic $\log$ can then be plotted as a velocity deviation log (Eq. 2):

$$
\text { Eq. 2. } \mathrm{VDL}=\text { Real velocity }- \text { Synthetic velocity } * 1000
$$

On the basis of the deviation of the synthetic log, the pore types are classified into three categories: positive deviation, zero deviation and negative deviation. It should be noted that in the current study we focus on the negative deviations as indicator of fractured intervals.

There are three possible explanations for zones with the negative deviation. First, it could be the result of caving or irregularities of the borehole wall. Another reason for the negative deviation is fracturing. Despite the fact that fracture porosity has always been included in the secondary porosity (equivalent to high velocity or positive deviations, Schlumberger, 1991), several studies showed that fracturing decreases velocities on both small (Anselmetti and Eberli, 1999) and large (Guadagno and Nunziata, 1993) scales. The large scale fractures can be detected by using the logging tools in which they yield lower velocities than the undisturbed rock. In addition, the buried fractures are generally closed or negligible so that the neutron porosity is not reduced, considerably. As a result, fracturing produces negative deviations. Negative deviations could also be caused by a high content of free gas. Free gas 
would have a strong negative effect on the deviation log because gas drastically reduces the velocity of Pwave (Vp) (Nur and Simmons, 1969) and results in a reduced neutron porosity reading as a result of the lower content of hydrogen in the fluid phase (Hilchie, 1982).

Using the above procedure the VDL was calculated for three wells of the study area and the results were then incorporated into the reservoir model (Fig. 6a). As is seen in Fig. 6, distribution of the zones with negative velocity deviations is relatively high in the central parts of the section around the normal faults (around wells\#1 and \#2). In addition, there is a noteworthy reduction in the amount of negative deviation in the footwall and around well \#3 which is located far away from the normal faults.

\subsubsection{The fracture intensity model}

Formation Micro Imager (FMI) is an ideal tool for identifying and evaluating fractures. It provides nearly full-bore coverage in 8 inch boreholes with an image resolution of 0.2 inch and can record all features along the borehole wall (Schlumberger education services, 1991). The FMI log is an essential element of this study.

The natural open fractures were identified though processing and interpretation of FMI logs. For every fracture a point is plotted and finally a continuous fracture density log was created. Note that a window with a fixed length must be considered representing the average value of fractures within each interval. Hence, it can dismiss the impact of single fracture and provides an appropriate vision of the fracture intensity $\log$.

Fracture intensity logs were derived for the three wells (well\#1, \#2 and \#3, Fig. 1c) from interpretation of FMI logs (Fig. 6b). The fracture intensity distribution is high within the normal faults domain, especially in the central parts of the study area and also in the hanging wall of the faults. In contrast, the

fracture intensity becomes extremely low in the footwall of the faults where the well\#3 is located. As is seen, there is a direct correlation between fracture intensity and negative velocity deviation. 


\subsection{Appraisal of rock physics properties in the normal faults domain}

In this section, the possibility of fractures presence is assessed by combination of rock-physics data obtained from the well-logs and 2D post-stack seismic data. The aim is to exploit the link between in-situ physical properties of reservoirs rock and critical reservoir characteristics to evaluate the probability of fractures presence in a particular unit. An attempt is also made to use the acoustic wave velocity measurements (compressional-wave and shear-wave) to determine geomechanical parameters through inverse modeling techniques.

\subsubsection{Inversion modeling}

Inversion enables geoscientists to extract more insight from geophysical data by converting geophysical measurements into 3D images of the subsurface state that can be integrated with other surface and subsurface geologic observations. Insights generated from geophysical inversion have helped to improve prospecting and focus drill targeting, particularly in deeper and more complex subsurface environments (Russell, 2004). In this section, based on the available data, the post-stack inversion technique has been employed. After primary quality control of data, the check-shot data and full-set DT log data from well\#2 and well\#4 were used in order to create a velocity model for the time-depth domain conversion.

Initially, the average composite trace derived from the $2 \mathrm{D}$ post-stack seismic data is correlated with the synthetic trace constructed from density and sonic well-logs. After an acceptable and reliable correlation coefficient between two types of traces has been achieved, a single wavelet is extracted from the well. Afterwards, the model-based inversion algorithm is used in conjunction with others techniques such as travel-time inversion, wave-field inversion and recursive Inversion. In this algorithm, the initial acoustic impedance model is used as it tends to decrease the correlation error between the synthetic and the real seismic trace (Russell, 2004). The algorithm applied involves a repetitive update of an impedance model in order to obtain the best match between the synthetic and real seismic trace (Russell, 2004; Guliyev, 2007). The schematic workflow of the inversion algorithm is illustrated in Figure 7.

After performing the seismic inversion, the geomechanical parameters and shear-wave have been upscaled from well scale to seismic profile scale in order to model the inter-wells spaces. Because the elastic 
properties are scale-dependent, up-scaling is imperative in order to use of these parameters in the fieldscale, (Rivenæs, 2011; Bisaso, 2011). Therefore, to construction of these characteristics the attributes were derived from inverted post-stack seismic data and the best attributes, i.e. those with minimum average error and maximum matching with the geomechanical parameters and shear wave velocity, have been selected. Because complex and non-linear relationships exist between seismic attributes and the target parameters, probabilistic neural networks were used in order to estimate geomechanical properties.

\subsubsection{Investigation of the velocity anomalies}

Elastic waves are sensitive to physical properties of rocks and considering the impact of elastic properties on scattering of elastic waves' velocity, variations in waves' velocity can be interpreted as changes in the physical properties of the rock. According to the Pickett (1963), it was found that limestone has approximately a high value of $\mathrm{Vp} / \mathrm{Vs}$ (1.8 to 2.0$)$.

Also regarding the reduction of Vs under natural fracture, and because of zero value of shear modulus in gases and fluids, the wave is not influenced by fluid and gas; so, its variation was considered as the basis of recognition of anomalies caused by fractures. However, $\mathrm{Vp}$ is deprived of such positive characteristics for prediction of fractures. The relationships between the rock properties and the wave velocities are expressed as follows.

$$
\begin{gathered}
\text { Eq.3. } \quad V s=\sqrt{\frac{\mu}{\rho}} \\
\text { Eq.4. } \quad V p=\sqrt{\frac{k+4 / 3 \mu}{\rho}}
\end{gathered}
$$

where $\mu$ and $k$ are the shear modulus and bulk modulus, respectively and $\rho$ is the density.

As shown in Figure 8, the in-situ shear-wave velocity variations versus the ratio of $\mathrm{Vp} / \mathrm{Vs}$ were studied. It is seen that the velocity's anomalies exist in the central part of the study area. In these regions, shearwave velocity reduced and consequently $\mathrm{Vp} / \mathrm{Vs}$ ratio increased. On the other hand, $\mathrm{Vp} / \mathrm{Vs}$ ratio increases in the porous zones indicating the probability of fractures presence (Fig.8). It is expected formation density should be reduced that as fractures density increases and consequently the shear-wave velocity 
shows a decrease (Figure 9). Note that the parameters were measured directly and were not derived from empirical relationships.

As well as, Vs variation was up-scaled to seismic data scale between well\#2 and well\#6, parallel to the structure to depict probable zones (Figure 10a). As it is seen, away from the two wells and towards the center of the field, low velocity zones increase. That is, the shear wave velocity reduced towards the center of area.

\subsubsection{Estimation of the geomechanical parameters by using inversion modeling}

The geomechanical parameters of the reservoir rocks can be determined based on their impact on elastic waves. Empirical relationship between the shear and compressive wave velocity and Poisson's ratio (PR) has been presented by Brocher (2005).

$$
\begin{gathered}
E q .5 . \quad P R=0.8835-0.315 V p+0.0491 V p^{2}-0.0024 V p^{3} \\
E q .6 . \quad E=2 \rho V_{s}^{2}(1+P R)
\end{gathered}
$$

where PR and E are the Poisson's ratio and the Young's modulus, respectively. Such relationships are valid for the upper crustal rocks where $\mathrm{Vp}$ is between 1.5 to $8.5 \mathrm{~km} / \mathrm{s}$. As illustrated in Fig. 10b, the zones with lower values of Poisson's ratio appear in the faulted zone. It is suggested that such anomalies are responsible for fault related fractures. Inversion modeling shows a similar drop in Young's modulus (Fig.10c) in the same zones in which the Poisson's ratio decreases. This could also be attributed to the presence of fractures.

\subsection{Determine of the fractures role in the reservoir characteristics}

Formation Micro Imager (FMI) or Formation Micro Scanner (FMS) logs are particularly helpful in improving our understanding of fracture properties, but conventional logs are also still very useful as they can provide essential fracture information (Yan et al., 2009). Currently, high resolution data acquisition devices (like image logs) can detect small-scale variations and discontinuities in rocks. Unfortunately, for thousands of wells drilled before the introduction of these new technologies, no such image log data are 
available (Tokhmchi et al., 2010). It is noted however that the Identification of geological structures when only image logs are available is difficult and sometimes may yield incorrect results (Lin et al., 2010).

In the present study, a variety of data sources have been employed to determine the effect of fracture system on the secondary porosity and permeability. These include FMI logs, fracture density derived from

FMI log interpretation and secondary porosity derived from conventional logs (Fig. 11). The resulting model was then correlated to the core data (RCAL) which are available for an interval of about $150 \mathrm{~m}$.

It should be noted that the fractures and vugs are of the main causers of permeability increase in the studied field. According to the Pie chart generated from the RCAL data of well\#1 (Fig. 12), the contribution of vertical open fractures, horizontal fractures and vugs in permeability increase is $42 \%, 56 \%$ and $2 \%$ respectively.

It is noteworthy that prior to fracture analysis from well logs, shale effect was removed by employing GR/HGR (gamma ray and hostile gamma ray) logs.

As shown in Fig. 13, running K-Means algorithm of clustering indicates three classes of porosity/permeability for the fractured samples. The correlation between porosity and permeability is low within each cluster. Final cluster centers and their distance from centers are shown in Figure 14. First cluster includes 69 percent of the dataset. Such a low correlation is attributed to the carbonate nature of the reservoir which causes complexities in petrophysical properties and pore throat network.

As it will be seen in next the section, more satisfactory results for fracture characterization is achieved based on porosity/permeability relationship through application of flow units concept.

\subsubsection{Flow Zone Index (FZI) Values in Fracture Pore Type}

The crucial parameter that controls reservoir quality and fluid flow in porous media is the pore system structure such as pore types and pore throat connectivity. A flow unit is defined as representative volume of a reservoir having similar pore geometry or pore throat characteristics (see e.g. Amaefule et al., 1993; Abbaszade et al., 1996). The pore type and size are primary controls on fluid movement in the reservoir 
and the variety of flow units and reservoir performance are dependent on the pore type distribution in the reservoir units.

The hydraulic flow units (HFU) are determined on the basis of rock quality index (RQI, $\mu \mathrm{m})$, effective porosity $\left(\varphi_{z}\right)$, permeability $(\mathrm{K}, \mathrm{mD})$, and normalized porosity $\left(\varphi_{z}\right)$ (equations 7-9):

$$
\begin{array}{lll}
\text { Eq.7. } R Q I=0.0314 \sqrt{\frac{K}{\varphi_{e}}} \quad \text { Eq.8. } \varphi_{z}=\frac{\varphi_{e}}{1-\varphi_{e}} \quad \text { Eq.9. } \quad F Z I=\frac{R Q I}{\varphi_{z}}
\end{array}
$$

where $\varphi_{e}$ is the effective porosity and FZI is the flow zone index $(\mu m)$.

Ideally, on the semi-log plot of $\mathrm{K}$ versus $\varphi_{z}$, samples with similar FZI values have unit slop. Samples that lie on the same straight line have similar pore throat attributes, so constitute a unique hydraulic flow unit.

Hydraulic Flow Unit (HFU) technique was employed for more detailed classification of reservoir rocks in the framework of porosity-permeability relationship. This technique is mainly used for reservoirs zonation and rock types classification, but here it is used for recognition of fractured rock classes. Normally, fractured rocks exhibit high horizontal and vertical permeability even with low porosity values. Flow zone indicator (FZI) was calculated for each pair of porosity and permeability data and then they were categorized. As is seen in Fig. 15, seven series of HFU were determined for which the largest group of fractures belongs to HFU2 (25\% of whole data). As is seen in Fig. 15, the connection between fracture porosity and permeability is stronger in HFU 1.

\section{Summary and conclusion}

In this study, an attempt was made to identify the major origin of fractures in the Ilam-Sarvak carbonate reservoirs by using an in-situ stress analysis. Afterwards, 3D models showing the special distribution of velocity deviation and fracture intensity were constructed by using a sequential Gaussian simulation approach. The results demonstrated that there is a high probability of fractures occurrence in the IlamSarvak reservoirs, especially in the normal faults domain. Due to the structural heterogeneity and high uncertainty of the 3D models to predict data at inter-wells spaces, a geophysical modeling approach was applied to achieve more reliable and trustworthy results. 
The rock physics models were updated by using an advanced seismic interpretation technique. The regions with the minimum values of shear-wave velocity correspond to the lowest value of the Poisson's ratio and Young's modulus. There is a good agreement between the faulted and fractured zone and such areas showing the lowest values of rock elastic properties. In addition, assessment of the models in the framework of FMI log data revealed that fracture intensity decreased dramatically from hanging-wall to footwall where well \#4 is drilled.

Routine core analysis data in well\#1 revealed that the different types of fractures within the reservoir are responsible for a large proportion of secondary porosity (approximately 98\%) and that the vugs make only a minor contribution. And finally an attempt was made to classify the porosity-permeability values of the fractures through a suitable scheme. To accomplish this purpose, three distinctive methods were employed. Classification of the porosity-permeability values based on the type of fracture was unsuccessful. Classification based on K-Mean clustering approach did not show a promising correlation coefficient between porosity and permeability within each fracture class. However, using the hydraulic flow units approach a satisfactory correlation was established between porosity and permeability of the fractures.

The results exhibited that fracture pore type plays a significant role in controlling the petrophysical properties of the studied reservoir. Overall, the fracture system has been developed in the normal faults domain especially in their hanging-walls.

\section{Acknowledgment}

The authors would like to thank IOOC (Iranian Offshore Oil Company) for data preparation and permission to publish the results of this research. Also the authors are appreciative to Prof. J.W. Cosgrove from Imperial college of London for his valuable advice and constrictive review of the manuscript. 


\section{References}

Aadnoy, B.S., 1990. Inversion technique to determine the in-situ stress field from fracturing data. Journal of Petroleum Science and Engineering 4(2): 127-141.

Abbaszadeh, M., Fujii, H., Fujimoto, F., 1996. Permeability prediction by hydraulic flow units-theory and applications. SPE Formation Evaluation 11(04): 263-271.

Al-Dossary, S., Marfurt, K.J., 2006. 3D volumetric multispectral estimates of reflector curvature and rotation. Geophysics 71(5): P41-P51.

Allen, M., Jackson, J., Walker., R., 2004. Late Cenozoic reorganization of the Arabia-Eurasia collision and the comparison of short-term and long-term deformation rates. Tectonics 23(2).

Amaefule, J.O., Altunbay, M., Tiab, D., Kersey, D.G., Keelan, D.K., 1993. Enhanced reservoir description: using core and log data to identify hydraulic (flow) units and predict permeability in uncored intervals/wells. SPE Annual Technical Conference and Exhibition, Society of Petroleum Engineers. SPE26436-MS.

Anselmetti, F.S., Eberli, G.P., 1999. The velocity-deviation log: a tool to predict pore type and permeability trends in carbonate drill holes from sonic and porosity or density logs. AAPG bulletin 83(3): 450-466.

Aydin, A., 2000. Fractures, faults, and hydrocarbon entrapment, migration and flow. Marine and Petroleum Geology 17(7): 797-814.

Barton, C.A., Zoback, M.D., 2002. Discrimination of natural fractures from drilling-induced wellbore failures in wellbore image data-implications for reservoir permeability. SPE Reservoir Evaluation \& Engineering 5(03): 249-254. 
Bell, J., Gough, D., 1979. Northeast-southwest compressive stress in Alberta evidence from oil wells. Earth and Planetary Science Letters 45(2): 475-482.

Bellefleur, G., Malehmir, A., Müller, C., 2012. Elastic finite-difference modeling of volcanic-hosted massive sulfide deposits: A case study from Half Mile Lake, New Brunswick, Canada. Geophysics 77(5): WC25-WC36.

Berberian, M., 1995. Master "blind" thrust faults hidden under the Zagros folds: active basement tectonics and surface morphotectonics. Tectonophysics 241(3): 193-224.

Bisaso, I., 2011. Calibration of seismic and well data: Towards Improved Quantitative Seismic Reservoir Characterisation of the Triassic to Middle-Jurassic Gullfaks Reservoir Units of the northern North Sea. MSc Thesis, University of Bergen.

Bordenave, M., Hegre, J., 2005. The influence of tectonics on the entrapment of oil in the Dezful Embayment, Zagros Foldbelt, Iran. Journal of Petroleum Geology 28(4): 339-368.

Brocher, T.M., 2005. Empirical relations between elastic wavespeeds and density in the Earth's crust. Bulletin of the Seismological Society of America 95(6): 2081-2092.

Chopra, S., Marfurt, K.J., 2005. Seismic attributes-A historical perspective. Geophysics 70(5): 3SO$28 \mathrm{SO}$.

Chopra, S., Marfurt, K.J., 2010. Integration of coherence and volumetric curvature images. The Leading Edge 29(9): 1092-1107.

Chopra, S., Misra, S., Marfurt, K. J., 2011. Coherence and curvature attributes on preconditioned seismic data. The Leading Edge 30(4): 386-393. 
Dershowitz, B., LaPointe, P., Eiben, T., Wei, L., 2000. Integration of Discrete Feature Network Methods With Conventional Simulator Approaches. SPEREE 3 (2): 165-170, SPE-62498-PA. DOI: 10.2118/62498-PA.

Dorbath, L., Cuenot, N., Genter, A., Frogneux, M., 2009. Seismic response of the fractured and faulted granite of Soultz-sous-Forêts (France) to $5 \mathrm{~km}$ deep massive water injections. Geophysical Journal International 177(2): 653-675.

Dou, Q., Sun, Y., Sullivan, C., 2011. Rock-physics-based carbonate pore type characterization and reservoir permeability heterogeneity evaluation, Upper San Andres reservoir, Permian Basin, west Texas. Journal of Applied Geophysics 74(1): 8-18

Edgell, H., 1996. Salt tectonism in the Persian Gulf basin. Geological Society, London, Special Publications 100(1): 129-151.

Falcon, N.L., 1974. Southern Iran: Zagros Mountains. Geological Society, London, Special Publications 4(1): 199-211.

Guadagno, F., Nunziata, D.C., 1993. Seismic velocities of fractured carbonate rocks (southern Apennines, Italy). Geophysical Journal International 113(3): 739-746.

Guliyev, E., 2007. Vp/Vs estimation from multicomponent seismic data for improved characterization of a tight sandstone gas reservoir. Rulison field, Colorado: MS thesis, Colorado School of Mines.

Hajikazemi, E., Al-Aasm, I.S., Coniglio, M., 2010. Subaerial exposure and meteoric diagenesis of the Cenomanian-Turonian Upper Sarvak Formation, southwestern Iran. Geological Society, London, Special Publications 330(1): 253-272.

Harris, J.F., Taylor, G.L., Walper, J.L., 1960. Relation of deformational fractures in sedimentary rocks to regional and local structure. AAPG bulletin 44(12): 1853-1873. 
Hartigan, John A., and Manchek A. Wong., 1979. Algorithm AS 136: A k-means clustering algorithm. Applied statistics: 100-108.

Hilchie, D.W., 1982. Advanced well log interpretation, Douglas W. Hilchie, Inc., Golden Co., 353 p.

Hu, L., Ravalec-Dupin, M.Le., 2005. On Some Controversial Issues of Geostatistical Simulation. Geostatistics Banff 2004, Springer: 175-184.

Jenkins, C., Ouenes, A., Zellou, A., Wingard, J., 2009. Quantifying and predicting naturally fractured reservoir behavior with continuous fracture models. AAPG bulletin 93(11): 1597-1608.

Jolley, S., Barr, D., Walsh, J. J., Knipe, R. J. (2007). Structurally complex reservoirs: an introduction. Geological Society, London, Special Publications 292(1): 1-24.

Karimpouli, S., Hassani, H., Malehmir, A., Nabi-Bidhendi, M., Khoshdel, H. (2013). Understanding the fracture role on hydrocarbon accumulation and distribution using seismic data: A case study on a carbonate reservoir from Iran. Journal of Applied Geophysics 96: 98-106.

Khoshbakht, F., Azizzadeh, M., Memarian, H., Nourozi, G.H., Moallemi, S.A., 2012. Comparison of electrical image log with core in a fractured carbonate reservoir. Journal of Petroleum Science and Engineering 86: 289-296.

Konyuhov, A. Maleki, B., 2006. The Persian Gulf Basin: Geological history, sedimentary formations, and petroleum potential. Lithology and Mineral Resources 41(4): 344-361.

Kosari, E., Ghareh-Cheloo, S., Kadkhodaie-Ilkhchi, A., Bahroudi, A., 2015. Fracture characterization by fusion of geophysical and geomechanical data: a case study from the Asmari reservoir, the Central Zagros fold-thrust belt. Journal of Geophysics and Engineering, 12(1), 130. 
Lacombe, O., Bellahsen, N., Mouthereau, F., 2011. Fracture patterns in the Zagros Simply Folded Belt (Fars, Iran): constraints on early collisional tectonic history and role of basement faults. Geological Magazine 148(5-6): 940-963.

Lin, W., Yeh, E.C., Hung, J.H., Haimson, B., Hirono, T., 2010. Localized rotation of principal stress around faults and fractures determined from borehole breakouts in hole B of the Taiwan Chelungpu-fault Drilling Project (TCDP). Tectonophysics 482(1): 82-91.

Malehmir, A., Bellefleur, G., 2009. 3D seismic reflection imaging of volcanic-hosted massive sulfide deposits: Insights from reprocessing Halfmile Lake data, New Brunswick, Canada. Geophysics 74(6): B209-B219.

Malehmir, A., Schmelzbach, C., Bongajum, E., Bellefleur, G., Juhlin, C., Tryggvason, A., 2009. 3D constraints on a possible deep> $2.5 \mathrm{~km}$ massive sulphide mineralization from $2 \mathrm{D}$ crooked-line seismic reflection data in the Kristineberg mining area, northern Sweden. Tectonophysics 479(3): 223-240.

Manchuk, J., Leuangthong, O.Y., Deutsch, C.V., 2005. Direct Geostatistical Simulation on Unstructured Grids. Geostatistics Banff 2004, Springer: 85-94.

McQuarrie, N., Stock, J. M., Verdel, C., Wernicke, B.P., 2003. Cenozoic evolution of Neotethys and implications for the causes of plate motions. Geophysical Research Letters 30(20).

Nelson, R., 2001. Geologic analysis of naturally fractured reservoirs, Gulf Professional Publishing.

Nie, X., Zou, C., Pan, L., Huang, Z., Liu, D., 2013. Fracture analysis and determination of in-situ stress direction from resistivity and acoustic image logs and core data in the Wenchuan Earthquake Fault Scientific Drilling Borehole-2 (50-1370m). Tectonophysics 593: 161-171.

Nur, A. Simmons, G., 1969. Stress-induced velocity anisotropy in rock: An experimental study. Journal of Geophysical Research 74(27): 6667-6674. 
Pickett, G.R., 1963. Acoustic character logs and their applications in formation evaluation. Journal of Petroleum technology 15(06): 659-667.

Pyrcz, M.J. and C.V. Deutsch, 2014. Geostatistical reservoir modeling, Oxford university press.

Rajabi, M., Sherkati, S., Bohloli, B., Tingay, M. 2010. Subsurface fracture analysis and determination of in-situ stress direction using FMI logs: An example from the Santonian carbonates (Ilam Formation) in the Abadan Plain, Iran. Tectonophysics 492(1): 192-200.

Regard, V., Bellier, O., Thomas, J. C., Abbassi, M.R., Mercier, J., Shabanian, E., Feghhi, K., Soleymani, S., 2004. Accommodation of Arabia-Eurasia convergence in the Zagros-Makran transfer zone, SE Iran: A transition between collision and subduction through a young deforming system. Tectonics 23(4).

Roberts, A., 2001. Curvature attributes and their application to 3 D interpreted horizons. First break 19(2): $85-100$.

Russell, B.H., 2004. The application of multivariate statistics and neural networks to the prediction of reservoir parameters using seismic attributes. Ph.D. dissertation, University of Calgary, $367 \mathrm{p}$.

Sabathier, J., Bourbiaux, B.J., Cacas, M.C., Sarda, S., 1998. A new approach of fractured reservoirs. SPE international petroleum conference. SPE-39825-MS.

Sausse, J., Dezayes, C., Dorbath, L., Genter, A., Place, J., 2010. 3D model of fracture zones at Soultzsous-Forêts based on geological data, image logs, induced microseismicity and vertical seismic profiles. Comptes Rendus Geoscience 342(7): 531-545.

Schlumberger, 1991. Log interpretation principles/applications, Schlumberger Limited, New York, NY.

Serra, O., 1984. Fundamentals of Well-Log Interpretation (Vol. 1): The Acquisition of Logging Data: Dev. Pet. Sci. A 15. 
Sharp, I., Gillespie, P., Morsalnezhad, D., Taberner, C., Karpuz, R., Vergés, J., Horbury, A., Pickard, N., Garland, J., Hunt, D., 2010. Stratigraphic architecture and fracture-controlled dolomitization of the Cretaceous Khami and Bangestan groups: an outcrop case study, Zagros Mountains, Iran. Geological Society, London, Special Publications 329(1): 343-396.

Srivastava, R.M., Frykman, P., Jensen, M., 2005. Geostatistical simulation of fracture networks. Geostatistics Banff 2004, Springer: 295-304.

Tiab, D., Donaldson, E.C., 2011. Petrophysics: theory and practice of measuring reservoir rock and fluid transport properties, Gulf professional publishing.

Tingay, M., Muller, B., Reinecker, J., Heidbach, O., 2006). State and origin of the present-day stress field in sedimentary basins: New results from the World Stress Map Project. Golden Rocks 2006 The 41st US Symposium on Rock Mechanics (USRMS), American Rock Mechanics Association.

Tingay, M.R., Hillis, R., Morley, C.K., Swarbrick, R., Drake, S.J., 2005. Present-day stress orientation in Brunei: a snapshot of 'prograding tectonics' in a Tertiary delta. Journal of the Geological Society 162(1): $39-49$.

Tokhmchi, B., Memarian, H., Rezaee, M.R., 2010. Estimation of the fracture density in fractured zones using petrophysical logs. Journal of Petroleum Science and Engineering 72(1): 206-213.

Tsvankin, I., Gaiser, J., Grechka, V., van der Baan, M., Thomsen, L., 2010. Seismic anisotropy in exploration and reservoir characterization: An overview. Geophysics 75(5): 75A15-75A29.

Van Buchem, F., Allan, T., Laursen, G.V., Lotfpour, M., Moallemi, A., Monibi, S., Motiei, H., Pickard, N., Tahmasbi, A.R., Vedrenne, V. 2010. Regional stratigraphic architecture and reservoir types of the Oligo-Miocene deposits in the Dezful Embayment (Asmari and Pabdeh Formations) SW Iran. Geological Society, London, Special Publications 329(1): 219-263. 
Vernant, P., Nilforoushan, F., Hatzfeld, D., Abbassi, M. R., Vigny, C., Masson, F., Nankali, H., Martinod, J., Ashtiani, A., Bayer, R., 2004. Present-day crustal deformation and plate kinematics in the Middle East constrained by GPS measurements in Iran and northern Oman. Geophysical Journal International 157(1): 381-398.

Yan, J., Lu, L.W., Lubbe, R., Payne, S., 2009. Petrophysical fracture identification for rock physics studies. 71st EAGE Conference \& Exhibition.

Zazoun, R.S., 2013. Fracture density estimation from core and conventional well logs data using artificial neural networks: The Cambro-Ordovician reservoir of Mesdar oil field, Algeria. Journal of African Earth Sciences 83: 55-73.

Zoback, M.D., 2007. Reservoir geomechanics: Earth stress and rock mechanics applied to exploration, production and wellbore stability, Cambridge Press, Cambridge Press. 


\section{Figure captions}

Figure1: (a) Topographic map of the Middle East with plate relative movement; (b) Tectonic subdivisions and main structural features of the Zagros fold-thrust belt location of the study area close to Strait of Hormuz (c) Underground depth map of the reservoir structure with the used well positions.

Figure 2: Stratigraphic table of the studied area. The Kazhdumi, Sarvak-Ilam and Gurpi formations include source, reservoir and cap rocks of the field, respectively.

Figure 3: 2D seismic profiles perpendicular (a) and parallel (b) to the hydrocarbon field's structure in order to illustration of the structure's geometry and the mechanism of the main faults. MWF: Main Western Fault (Inverted reverse mechanism), MEF: Main Eastern Fault (Reverse mechanism). CRE, GUR, IL-SAR, KAZ and DAR are tops of Cretaceous, Gurpi, Ilam-Sarvak and Darian formations, respectively; vertical scale is in seconds of two-way travel time (TWT) (c) Underground Contour (UGC) map of the reservoir, the UGC illustrates location of main faults.

Figure 4: Demonstration of discontinuities including, open natural fracture, drilling induced-fractures (DIFs) and Breakouts (BOs) in the wellbores by dynamic Formation Micro Imager (FMI).

Figure 5: Rose diagram showing the orientation of breakouts (blue), Drilling induced-fractures (red) and open natural fractures (white): the principle in-situ stresses directions: Maximum horizontal in-situ stress is parallel to the tensile induced fractures strike (orange) and the minimum horizontal in-situ stress is parallel to breakouts strike (yellow).

Figure 6: Profiles of the constructed geostatistics models of distribution of fracture density parallel to the main structure direction in the normal faults domain; (a) cool colors display probable dense fractured zone estimated from FIL; (b) detours of the Velocity Deviation Log; cool colors indicates the probable dense fractured zones. The dashed red and blue lines specified location of the normal faults. Width of the profile is approximately $5 \mathrm{~km}$. 
Figure 7: The schematic workflow of the model-based inversion algorithm (modified after Russell, 2004).

Figure 8: Measured neutron porosity versus Vp/Vs ratio in well\#3 (for the well location refer to the Fig. 1) which has high fracture intensity in the reservoir zone (left), note to the displayed anomalies; shearwave velocity versus $\mathrm{Vp} / \mathrm{Vs}$ ration (right), the blue arrow suggests increase of fracture probability and the dark pink arrow suggests decrease of fracture probability.

Figure 9: Directly measured Formation density versus shear-wave velocity in the reservoir interval.

Figure 10: The constructed inverted models of distribution of Vs variation (a), Poisson's ratio (b) and Young's modulus (c); the dashed lines showed top and base of the carbonate reservoir. The dashed polygons and back arrows display the probable fractured zone located in the normal faults domain between well\#1 and well\#4 parallel to the structure by relying on lower values of the mentioned parameters.

Figure 11: (a) Exhibition of fracture density log derived from FMI and absolute secondary porosity in well\#2, (b) fracture density log derived from FMI and relative secondary porosity including, vugs and fractures derived from FMI in well\#4.

Figure 12: The percent of communion of secondary features in the permeability.

Figure 13: Fracture's porosity versus fractures permeability by K-Mean clustering method. Note to the unreliable correlation coefficient.

Figure 14: The results of running k-means algorithm for classification of porosity and permeability of fractures. As is seen, three clusters are extracted and the values presented in part (a) represent the initial clusters centers or average values of fracture porosity and permeability within each cluster. Part (b) renders final centers of the porosity-permeability clusters and part (c) indicates distance of clusters from centers. 
Figure 15: Illustration of seven sets of the hydraulic flow units based on their corresponding FZI intervals. Each set has its own correlation coefficients (ranging from about $60 \%$ to $90 \%$ ). All trend-lines demonstrate a good degree of correlation. 